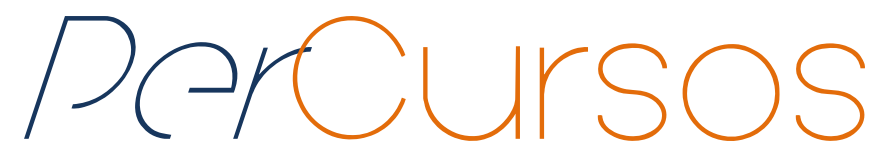

\title{
Entre as margens dos rios e as marchas da história: espaço e sociedade ribeirinha na Amazônia ${ }^{1}$
}

\section{Resumo}

O artigo expõe em largos traços o processo histórico de constituição da sociedade e do espaço ribeirinho da Amazônia. Partimos do entendimento que as sociedades ribeirinhas expressam as primeiras formas de produção do espaço amazônico edificadas sobre o contexto mercantil a partir da chegada dos colonizadores. Ressaltamos que suas condições de vida emergem da inserção desses grupos no contexto de formação espacial da Amazônia, desde a chegada do colonizador perpassando por diversas outras fases de ocupação da região. É nessa circunstância que vislumbramos a resistência dos modos de vida destas populações manifesta na criação e recriação de saberes, fazeres e estratégias que remontam à sabedoria de seus antepassados, aprimorada por gerações. Contribuímos num campo de pesquisa que busca analisar a trajetória destes grupos tendo como foco o diálogo entre espaço e sociedade. Inicialmente, refletimos sobre o processo de inserção dos povos ribeirinhos na constituição da sociedade colonial mercantil tendo em vista o delineamento das primeiras bases de formação do meio natural amazônico. Em seguida mostramos a reverberação desse processo sobre a constituição da sociedade ribeirinha em fases posteriores de formação espacial da região, especialmente no período de desenvolvimento da economia da borracha.

Palavras-chave: Amazônia. Ribeirinhos. Colonização. Economia da borracha.

\section{João Santos Nahum}

Doutor em Geografia pela UNESPRio Claro. Professor da Faculdade de Geografia e Cartografia e do Programa de Pós-Graduação em

Geografia da Universidade Federal do Pará - UFPA.

Brasil

prof.joaonahum@gmail.com

\section{Denison da Silva Ferreira}

Doutorando do Programa de PósGraduação em Geografia Univ.

Federal do Pará - UFPA.

Docente da rede pública estadual de ensino do Pará. Brasil

denisonferreira2010@hotmail.com

\footnotetext{
Para citar este artigo:

NAHUM, João Santos; FERREIRA, Denison da Silva. Entre as margens dos rios e as marchas da história: espaço e sociedade ribeirinha na Amazônia. Revista PerCursos, Florianópolis, v. 20, n.43, p. 39 - 65, maio/ago. 2019.
}

\section{DOI: $10.5965 / 1984724620432019039$}

http://dx.doi.org/10.5965/1984724620432019039

\footnotetext{
${ }^{1}$ Artigo fruto do projeto de pesquisa Formação Territorial e Rural da Amazônia.
} 


\title{
Between the river's margins and the history's marches: riverside space and society in
}

\section{Amazon}

\begin{abstract}
The article approaches the historical process of constitution of Amazon's society and the of riverside space. We start from the understanding that the riverside societies express the first forms of production of the Amazonian space built on the mercantile context from the arrival of the colonizers. We emphasize that their living conditions emerge from the insertion of these groups in the context of the spatial formation of the Amazon, since the arrival of colonizers, passing through several other phases of occupation of the region. It is in this context that we glimpse the resistance of the ways of life of these populations, manifest in creation and recreation of knowledge, actions and strategies that go back to their ancestor's wisdom, improved by generations and members in that trajectory of these populations. We contribute to a research field that seeks to analyze these groups trajectory, focusing on the dialogue between space and society. Initially we reflect on the process of insertion of the riverside peoples in constitution of the mercantile colonial society. Then we show the reverberation of this project on the constitution of the riverside society in posterior phases of the spatial formation, especially in the development period of rubber economy.
\end{abstract}

Keywords: Amazon. Riversides Colonization. Rubber economy. 


\section{Introdução}

Maués (1999) convida-nos a pensar numa outra invenção da Amazônia. Para tanto, identifica várias Amazônias, ressaltando que além da biodiversidade da fauna e flora da hileia, destaca-se a rica sociodiversidade expressa nos povos e grupos de indígenas, agricultores, seringueiros, varzeiros, castanheiros, quilombolas, ribeirinhos, dentre outros, cuja tradição étnico-cultural agrega heranças do ameríndio, do europeu e do negro desterrado da África. Estamos diante de grupos sociais de territorialidades múltiplas, cuja existência foi interpretada à luz de categorias e noções tais como campesinato histórico (HÉBETTE, 2002), populações tradicionais (DIEGUES, 1996), povos autóctones (RIBEIRO, 1995), dentre outros.

Partimos do entendimento que as sociedades ribeirinhas expressam as primeiras formas de produção do espaço amazônico sobre o contexto mercantil, edificadas a partir da chegada dos colonizadores, pois os ribeirinhos "estão diretamente ligados biológica, histórica e culturalmente à população ameríndia que ocupava a planície Amazônica na época do contato com os europeus" (WITKOSKI, 2007, p. 97). Tocantins (1961), Ribeiro (1995), Arenz (2000) e Witkoski (2007) notam que as sociedades ribeirinhas da Amazônia tiveram seus modos de vida profundamente alterados a partir da reorganização de uma economia regional orientada por interesses dominantes da empresa colonizadora europeia. Empresa associada e promotora de um modelo eurocêntrico de civilização que subjugou as populações aqui estabelecidas embora dependesse do seu conhecimento para realizar seus empreendimentos econômicos. Ademais, nas políticas de Estado para a organização regional tais como os Planos de Desenvolvimento da Amazônia (PDAs), em pleno século XX, esses grupos são representados como setor atrasado da economia e que deve ser removido para realização dos projetos pensados de fora da região e sempre alheios às suas demandas (NAHUM, 2013).

Como em Nahum (2019b), entende-se por sociedade ribeirinha aquela que tem seu "modo de vida construído no sistema de várzea e em torno dos rios. As atividades de criar, cultivar, extrair, produzir, o culto, a cultura, em suma, os saberes e fazeres são elaborados a partir de processos de adaptabilidade do rio aos moradores e dos 
moradores aos rios". Assim, as sociedades ribeirinhas não se definem por um povoado construído às margens de um curso d'água. Essa condição é insuficiente pois “o ribeirinho define-se por sua fluvialidade, isto é, as pessoas moram às margens do rio, mas o rio mora nas pessoas, numa espécie de pertencer aquilo que Ihes pertence” (Nahum, 2019b). Portanto, é preciso considerar que suas condições de vida emergem da inserção desses grupos no contexto mais amplo de formação espacial da Amazônia, sobretudo a partir da chegada do colonizador.

Delineamos aspectos constitutivos do espaço e da sociedade ribeirinha, ressaltando sua inserção na estruturação da região, sobretudo a partir da chegada do colonizador perpassando pelo período da economia da borracha, considerado um importante momento da formação amazônica. Partimos da hipótese de pesquisa de Arenz (2000) que situa no período entre o século XVIII e XIX a estruturação das sociedades ribeirinhas do baixo Amazonas emergindo entre aldeamentos e a produção de vilas de colonos. Assim, longe de estabelecer qualquer parecer definitivo sobre o tema, procuramos contribuir no debate envolvendo as sociedades tradicionais na Amazônia, considerando a necessidade de aprofundamento de estudos sobre as peculiaridades do movimento de constituição e dinamismo da região na contemporaneidade.

Adentramos num campo de pesquisas que têm nos trabalhos de Tocantins (1961), Wagley (1988), Weinstein (1993), Furtado (1993), Hiraoka (1993), Porro (1995), Ribeiro (1995), Maués (1999), Mcgrath, (1991), Silva (2000), Arenz (2000), Meggers(1987), Witkoski (2007) algumas interpretações da história social, econômica e cultural da Amazônia. Análises que não privilegiam diretamente as relações entre espaço e sociedade. É considerando isso que tateamos tais relações tendo como foco a sociedade ribeirinha. Na Amazônia, vários processos históricos e econômicos possibilitaram a transformação da natureza em meio natural. Expomos as linhas gerais estruturantes da sociedade e o espaço ribeirinho a partir do processo de colonização portuguesa responsável pela produção do meio natural alicerçado na sociedade mercantil. É nesse meio, resultante de tensões, disputas, conflitos e assimilação dos saberes e fazeres dos 
colonizadores europeus, ameríndios, africanos escravizados e migrantes brasileiros, sobretudo nordestinos, que se forma o modo de vida ribeirinho.

\section{Traços do meio natural da Amazônia}

Gondim (2007) analisa a invenção da Amazônia no imaginário europeu enquanto El dorado fomentador de empreendimentos coloniais. Benchimol (2009), por sua vez, propõe o termo amazonização para explicar o longo processo de construção e distinção da sociedade e cultura amazônica no cenário nacional. Em sua pesquisa sobre a formação territorial e rural da Amazônia oriental, tendo como fio condutor a sucessão e coexistência de meios geográficos, Nahum (2019) menciona que no meio natural amazônico o colonizador, seja por etnocídio ou genocídio, assimila e ressignifica da sabedoria indígena saberes e fazeres que lhe permitem apropriar e usufruir dos recursos dos corpos d'água e seus caminhos, fauna e flora das matas de igapó. Essa apropriação, orientada pela calha dos rios da bacia amazônica, coloniza áreas de várzea, adentra a mata de igapó e se expande pela terra firme fomentando o imaginário da região Amazônica enquanto uma vasta fonte de riquezas naturais.

Para Nahum (2019), no meio natural, cujo evento é a fundação de Belém em 1616 e se estende até a Operação Amazônia em 1966, forma-se a sociedade colonial mercantil sob o capital rentista alicerçado no binômio grande propriedade destinada à exportação e pequena propriedade responsável pelo abastecimento interno. A terra torna-se o principal meio de produção em que criar, cultivar, extrair e produzir ritmam-se nos ciclos dos reinos mineral, vegetal e animal. Constrói-se uma estrutura fundiária na qual convivem compulsória e conflituosamente uso e posse da terra, cultura de exportação/cultura de consumo interno com a primazia da propriedade sobre o uso, responsável pela alquímica renda da terra extraída junto àqueles que a usavam sem ter sua posse ou mesmo forjada por meio do trabalho compulsório dirigido pela empresa missionária, diretório pombalino, casas comerciais de cacau, madeira, peixe seco, borracha e castanha (HARRIS, 2017). 
Aldeias, vilas e cidades umbilicalmente dependentes do meio natural originaram-se da regulação espacial associada ao ordenamento jurídico colonial. Até o final do século XVIII as instituições religiosas, os comerciantes e o Estado português constituem os principais agentes delineadores da produção do espaço alicerçada numa economia extrativista que tem na atividade agrícola um setor secundário. Para Nahum (2019), no meio geográfico natural, predomina o que Altvater (2010) designa de sociedades solares, dependentes da energia solar e vivificadas por modos de vida construídos em torno das estações do ano. Trata-se de espaço pré-técnico no qual os saberes e fazeres herdados dos povos ameríndios se materializavam em instrumentos de trabalho, extensão do corpo do homem ou do animal. Nesse momento, o rio é a rua e comanda a vida (Tocantins, 2000) mas, a partir do século XIX, o capital comercial controla a navegação e insere a Amazônia na reprodução ampliada do capital quando utiliza o rio para circular produtos, serviços, bens e pessoas que dinamizam a economia em torno da produção de mercadoria e não da produção na terra (NAHUM, 2019).

Nesse período, consoante Nahum e Santos (2017), estrutura-se a condição espacial camponesa a partir da apropriação colonizadora das terras tupiniquins e da imposição da atividade econômica para fins de mercado. Aliás, uma das tarefas fundamentais da empresa colonial na Amazônia foi incluir a propriedade da terra na reprodução ampliada do capital, colocando-se de imediato a produção espacial do campo e do camponês em lugares onde não havia sociedades e comunidades camponesas, somente povos e nações denominados genericamente "indígenas" pelo colonizador.

Para Nahum e Santos (2017), a produção espacial do campo é imprescindível à dinâmica rentista brasileira que tem no monopólio da posse da terra o seu núcleo estruturador. Nesse espaço se reproduzem dialeticamente relações sociais de produção que permitem à empresa capitalista agroexportadora monopolizar as melhores terras, maiores linhas de créditos, incentivos fiscais e infraestrutura; restando à pequena produção familiar as demais áreas, frequentemente distantes das cidades, cuja cultura popular denomina de sítios, lugares de vida e trabalho construído por homens livres, alforriados, aquilombados, dentre outros tantos. 
Na região amazônica, os mecanismos políticos e econômicos de interdição dos ribeirinhos ao acesso à terra englobam as margens das densas e numerosas bacias hidrográficas. Na formação territorial e rural amazônica, segundo Nahum (2019), desde a fundação de Belém, em 1616, até a Operação Amazônia, em 1966, as cidades nasciam às margens dos rios e o urbano formava-se na margem onde a acumulação e reprodução do capital são mais densas e rápidas; espaço popularmente conhecido por beira. Os ribeirinhos, desde então, habitam a outra margem do rio, de onde apenas veem as luzes da cidade e os que para aí migram se distribuem pelo espaço popularmente conhecido por centro do continente, afastado da vida urbana.

Na leitura de Nahum (2019), durante esses três séculos e meio, a economia política do espaço revela a condição espacial ribeirinha; explica por que a sociedade ribeirinha se organiza na outra margem do rio e nos ajuda a entender a natureza da paisagem, da configuração espacial e dinâmica social, enfim do espaço habitado. Estamos diante da territorialidade de grupos que historicamente usam a terra sem ter sua posse jurídica, sem reconhecimento de legítimos proprietários, pois habitam espaços cujas atividades são incorporadas no processo de reprodução ampliada do capital, mas, não no processo produtivo direto, por isso vivem onde lhes foi concedido viver e trabalham numa terra que não lhes pertence.

Nesse período, tais espaços são marcados pela tensão entre a hegemonia da economia extrativista voltada para exportação e a necessidade de se desenvolver internamente a agropecuária para abastecimento da sociedade local (NAHUM, 2019). Os lugares são palco, produto e condicionante do dualismo econômico entre extrativismo exportador e agricultura local, tanto que muitos nasceram com a função de se tornarem colônias agrícolas, cuja função na divisão territorial do trabalho era produzir alimentos para o abastecimento interno. A produção apoia-se nos nascentes sistemas de engenharia de transporte, comunicação e informação que se distribuem pari passu com o volume, intensidade e perspectivas de produção, distribuição e comercialização (MARIN, 2004).

Podemos dizer que foram três séculos e meio de assenhoramento dos rios a partir do conhecimento das melhores rotas, como indica Albuquerque (1894), que 
em tão remota época (1853), muito mal regulamentado andava o serviço de praticagem em tal região; e menos ainda assegurada a sua navegação, tal a ausência de pharóes, boias e postos indicativos, e, sobretudo, a falta de conhecimentos especiais sobre as particularidades do curso das águas no Amazônas e seus afluentes. (ALBUQUERQUE,1894, p. 16)

No biênio de 1853-5, nota Albuquerque (1894), iniciou-se a navegação a vapor do Amazonas, por empreendedorismo de Irineu Evangelista de Souza a quem foi concedido pelo conselho presidencial do Pará, por meio do decreto n. 4037, de 30 de agosto de 1852, à Companhia de Navegação e Commercio do Amazônas o privilégio da navegação a vapor na região. Ao término do primeiro

decennio 1853-1863, a navegação regular a vapor desenvolvera-se de tal sorte, que multiplicaram-se as linhas, elevando-se ao número de oito, entre os seguintes portos principaes: Belém e Manáos, Manáos e Nauta (Perú), Manáos e Tabatinga, Manáos e Santa Isabel, Belém e Bayão (Tocantins), Belém e Chaves (Marajó), Belém e Itacoan (Marajó) e Belém e Soure (Marajó). (ALBUQUERQUE, 1894, p. 17)

Nesse período criam-se possibilidades para a acumulação primitiva do capital, sob a hegemonia do capital comercial e do discurso da dualidade espacial, moderno versus tradicional. A condição espacial ribeirinha na Amazônia se estabelece alicerçada em sistemas de produção extrativista onde estão irregularmente distribuídos os sistemas de energia, transporte, comunicação e informação.

No interior do meio natural, amadurecem as representações espaciais para emergência, em 1966, da Operação Amazônia. Conforme Nahum (2011), a Operação Amazônia reinventa a Amazônia, enquanto fronteira. Assim, lemos no relatório ministerial apresentado à consideração do senhor presidente da república pelo Ministro Extraordinário para Coordenação dos Organismos Regionais (MECOR):

Art. 1. Fica instituída, nos termos do presente Decreto, a Operação Amazônia com a finalidade precípua de mobilizar e coordenar os esforços governamentais que se orientarem em favor do 
desenvolvimento e da reformulação da política federal na região amazônica, no sentido de atualizar e dar novas prioridades a programas de desenvolvimento e de ocupação do território amazônico.

Art.2. Terão prioridade as providências de ordem legislativa e de regulamentação de tarefas executivas que tenham em mira a propositiva de alterações na legislação vigente, bem como a constituição de organismos públicos e privados, segundo o critério de articulação de ação federal respectiva, na área amazônica. (MECOR, [1960] p. 2)

Podemos dizer que a Operação Amazônia, tal como um evento (SANTOS, 2006), reorganiza a paisagem, a configuração espacial, a dinâmica social, enfim o espaço regional (SANTOS, 2006). No longo período natural amazônico criam-se os arranjos espaciais para a invenção da fronteira amazônica em 1966. Três séculos e meio onde, na região, impera a escassez dos sistemas de informação, comunicação, transporte rodoviário, aeroviário e sistema de energia elétrica. Por exemplo, de acordo com o Censo do IBGE de 1990, em 1907, na região Amazônica, podíamos encontrar telefones instalados somente nos estados do Pará - 388 instalações - e, do Amazonas, com 270 instalações; em 1944, a telefonia chega a Rondônia - 80 unidades -, Roraima, com 37 unidades e Acre, com 02 unidades; em 1961, finalmente, chega no Amapá a telefonia, com a instalação de 96 unidades. Tal escassez associada ao vazio demográfico e à dispersão demográfica fomenta a representação de vazio, como se espaço habitado e área fossem sinônimos.

A representação de vazio demográfico soma-se à de natureza enquanto fonte de recursos do solo, subsolo, rios, fauna e flora que deveriam ser aproveitados gerando emprego, renda e inclusão social. Cria-se a formação discursiva para emergência da ideia de fronteira amazônica enquanto espaço para reprodução do capital viabilizado autoritariamente pelo bloco de poder que assume a hegemonia da estrutura estatal a partir do golpe civil-militar de 1964 (NAHUM e SANTOS, 2017).

\section{Os primórdios da Amazônia ribeirinha}

Os dois primeiros séculos de colonização portuguesa na Amazônia foram decisivos na organização das sociedades ribeirinhas. Na perspectiva de Arenz, 
[...] a modelação da população ribeirinha na Amazônia abrange o período do início do século XVII (1616, fundação de Belém) até meados do século XIX (1870, início do ciclo da borracha). Este tempo de, aproximadamente, 250 anos está marcado por uma constante luta por parte da sociedade colonial e - a partir da independência - nacional, pelo acesso livre à mãode-obra barata indígena. (ARENZ (2000.p. 13)

A apropriação da Amazônia pelos europeus "nasceu sob o signo da disputa territorial de uma geopolítica de caráter colonial” (GONÇALVES, 2001, p. 80). Em um primeiro momento se deu percorrendo o rio Amazonas e seus tributários que constituíram ambientes privilegiados para estruturar núcleos de povoamentos e pequenas vilas. Assim,

[...] fora na região de várzea que os colonizadores europeus fundaram suas povoações e fortificações militares contribuindo para a despovoação das aldeias indígenas e substituindo-as por suas formas de povoamento fortemente marcadas por duas vertentes: as missões e as fortificações militares situadas nas margens dos rios. (BEZERRA NETO, 2001, p. 22)

A produção do espaço colonial português na Amazônia orienta-se, inicialmente, para a expulsão de estrangeiros das margens setentrionais do rio Amazonas perto de sua embocadura, travando disputas e construindo fortificações. Após a expulsão dos franceses de São Luiz do Maranhão, os portugueses estabeleceram-se numa ponta de terra proeminente da Baia Guajará numa construção de madeira, o Forte do Presépio, em 1616. Forte testemunha do projeto ambicioso, a começar pelo nome, Feliz Lusitânia e Nossa Senhora de Belém do Grão-Pará, com que foi batizado o lugar. O objetivo inicial dos portugueses “era 'limpar' a área, e especialmente as fronteiras, dos outros europeus interessados na sua exploração e assumir, politicamente, a direção da ocupação do território" (SILVA, 1996, p. 23). O controle geopolítico da foz do rio Amazonas foi decisivo para o domínio da região. A partir do povoamento em torno do Forte do Presépio, os portugueses puderam efetivamente expandir o domínio político e territorial para outras áreas da Amazônia. 
Consolidado esse momento, segue-se a prospecção e exploração econômica da região, configurando o que Costa (2000) denominou de formação extrativista regional. No tocante aos interesses comerciais, os colonizadores portugueses conquistavam aldeias e transformavam os ameríndios em mão de obra principal especialmente para coleta das drogas do sertão (RIBEIRO, 1995). Instaurava-se assim o aldeamento, primeiro sistema de controle territorial imposto sobre os ameríndios da Amazônia (MACHADO, 1997). Segundo Wagley (1988), a partir do regime de aldeamentos, os missionários, especialmente os jesuítas, estabeleceram-se em pontos estratégicos ao longo do rio Amazonas e de seus principais afluentes, atraindo ameríndios de várias tribos.

Nesse momento "levas de índios foram transportadas para as aldeias das missões, onde a vida passava a ser regulada por normas estabelecidas pelos missionários e onde se falava e ensinava a língua geral, uma forma modificada de Tupi-Guarani” (LOUREIRO, 2001, p. 291). Nas missões, convertiam-se gentios por meio da catequese e do trabalho metódico e regular, do ensino de novas artes manuais e dos costumes europeus. Assim, "num prazo relativamente curto milhares de índios [...] transformavam-se em "índios jesuítas' que viviam segundo os preceitos instituídos pelos padres jesuítas abandonando seus padrões culturais aborígines" (WAGLEY, 1988, p. 57). Dessa forma, a população nativa estava sob a cruz - representada pelo regime estritamente paternal dos jesuítas, através da catequização da população nativa sob os preceitos da Igreja Católica e a espada - traduzida pelo uso da força, comandada pelas expedições militares que visavam assegurar o controle do território e manter os índios sob o sistema escravista em razão de interesses econômicos (GONÇALVES, 2001). Em outros termos, a mesma cruz que abria os braços anunciando a liberdade, fechava os pulsos da opressão. Buscava-se "ocupar as almas enquanto se ocupava a terra" (LOUREIRO, 2001, p. 293).

Buscando formar a força de trabalho para a economia mercantil, os colonizadores, aliados aos missionários, empreenderam expedições comandadas pelas tropas de resgate de ameríndios rio acima para os aldeamentos. Para Ribeiro (1995), instaura-se um processo de recrutamento pela persuasão ou pela força de tribos inteiras em terra firme e nos altos cursos dos rios para os aldeamentos. Dessa forma, pensando nos ameríndios como gentios, nômades e bárbaros, os missionários procuravam descê-los para os 
aldeamentos e educá-los nos padrões que consideravam como cristãos e civilizados. O descimento consistiu na transferência de tribos de seus espaços de vida para os aldeamentos onde eram submetidos às novas condições de trabalho no convívio compulsório com outros troncos linguísticos e mesmo inimigos. Tal disciplina, imposta através do trabalho forçado e do convívio nos aldeamentos, impôs a homogeneização linguística e o enquadramento cultural compulsório do indígena no corpo de crenças e nos modos de vida dos seus cativadores, isto é, dos colonizadores (RIBEIRO, 1995).

Nessa situação, organizam-se sociedade e espaço ribeirinhos da Amazônia a partir de etnocídio, genocídio e aculturamento promovidos pelos aldeamentos missionários no século XVII, aprofundados pelo diretório pombalino na metade do século XVIII e pelas reformas pós-diretório no governo de Francisco de Souza Coutinho (HARRIS, 2017). Harris (2017, p. 138) menciona que "o diretório foi concebido para reestruturar a economia, atender às necessidades do Estado e para converter os índios missionados em vassalos adequados da Coroa”. Por sua vez, “a legislação pós-Diretório criou condições para que um campesinato semiautônomo viesse a se estabelecer em posição econômica mais forte na sociedade paraense, no começo do século XIX” (HARRIS, 2017, p. 152). A reverberação espacial disso é a elevação de aldeias em vilas erguidas às margens de rios.

Nos seus apontamentos para as efemérides paraenses, Barata (1973) registra datas ilustrativas da criação das vilas. Por exemplo, em 20 de janeiro de 1758 foi erigida a vila de Oeiras na antiga aldeia de Araticu, aldeia administrada pela Companhia de Jesus; em 23 de janeiro de 1758 foi elevada à vila, com o nome de Melgaço, a antiga aldeia Guaricurú, administrada pelos jesuítas; em 28 de fevereiro de 1758 foi elevada à vila de Monte Alegre, a antiga aldeia de Gurupatuba, administrada pelos religiosos da Piedade; em 06 de março de 1758 foi criada a vila de Alter do Chão no lugar da antiga aldeia Borori, administrada pela Companhia de Jesus; em 14 de março de 1758 foi elevada à vila de Santarém a antiga aldeia de Tapajós, administrada pelos Jesuítas; em 17 de março de 1732 foi elevada à vila Franca a antiga aldeia Cumaru administrada pelos jesuítas.

A elevação das aldeias a vilas é o testamento e testemunho da constituição do “estrato neo-indígena da população ribeirinha, constantemente renovado por novos descimentos devido à elevada mortalidade, à crescente demanda de braços e à própria 
filosofia das reduções religiosas" (PORRO, 1995, p. 14). Porro (1995) ressalta que as ações de descimento provocaram um despovoamento maciço e um repovoamento parcial em algumas áreas ribeirinhas do vale Amazônico. O despovoamento decorria da fuga dos habitantes tradicionais da várzea em função da escravização a que foram submetidos nos aldeamentos, além das epidemias trazidas pelo colonizador. Por sua vez, o repovoamento parcial resultava da inserção de tribos indígenas resgatadas pela força militar em áreas distantes da várzea.

O corolário desse processo foi o desaparecimento dos padrões adaptativos "da população original, que não chegaram a se reconstituir, a não ser parcialmente e a formação de um extrato que chamaremos neo-indígena inserido na sociedade colonial e marcado pelo desenraizamento e pela aculturação intertribal e inter-étnica" (PORRO, 1995, p. 38). Ribeiro (1995) destaca que através do contato inter-étnico e inter-tribal nos aldeamentos,

[...] foi surgindo uma população nova, herdeira da cultura tribal no que ela tinha de fórmula adaptativa à floresta tropical. Falava uma língua indígena, muito embora esta se difundisse como a língua da civilização, aprendida de brancos e mestiços. Identificava as plantas e os bichos da mata, as águas e as formas de vida aquática, os duendes e as visagens, segundo conceitos e termos das culturas originais. Provia sua subsistência através de roçados de mandioca, de milho e de algumas dezenas de outras culturas tropicais, também herdadas dos índios [...]. Ainda como os índios comia, dormia, vivia, enfim, no mundo de florestas e águas em que se ia instalando. Como os índios, finalmente, localizava e coletava na mata as especiarias cujo valor comercial tornava viável a ocupação neobrasileira da Amazônia e a vincularia à economia internacional. (RIBEIRO, 1995, p. 311-12)

Os aldeados se submeteram por completo ao sistema imposto pelos jesuítas. Foi essa a impressão do naturalista Henry Walter Bates na segunda metade do século XIX. Para Bates (1979, p. 39), “as tribos primitivas do distrito estão catequizadas agora, ou se misturaram com migrantes brancos e negros. Os nomes que distinguiam umas das outras foram esquecidos há muito tempo, e atualmente [1848] a raça é conhecida pelo nome genérico de tapuia”. Para Arenz (2000, p. 32), “houve também espaço para que criassem, 
a partir do seu próprio imaginário, uma cultura indígena de caráter genérico não mais especificamente tribal”, aproximando-os da religiosidade popular pouco ortodoxa entre os sucessores ribeirinhos baseada, por exemplo, em uma "crença popular de colcha de retalhos, fundada no sincretismo da pajelança indígena com um vago culto de santos e datas do calendário religioso católico" (RIBEIRO, 1995, p. 312).

Essa população nova, denominada por Porro (1995) de índio genérico, resultante do aldeamento, espalhou-se pelas margens dos rios constituindo um modo de vida ribeirinho. Conforme expõe Arenz (2000, p. 24), “dessa nova população descende o ribeirinho ameríndio atual", ou seja,

os índios, resgatados e descidos, disputados entre missionários e colonos, seriam a base para o surgimento dos ribeirinhos amazônicos. Especialmente nos aldeamentos dos religiosos, formou-se - dentro da complexidade do processo aculturador - uma cultura específica que os marca até hoje. (ARENZ, 2003, p. 35)

O aldeamento marcou a produção do espaço na várzea amazônica pelas sociedades ribeirinhas a partir do final do século XVII. No entanto, a introdução de elementos culturais pelos colonizadores não impediu que a população neo-indígena assimilasse técnicas essenciais ao ecossistema de várzea, assim como seus antepassados ameríndios, sobretudo, consoante Meggers (1987), a prática da agricultura considerando o movimento das marés e as estações do ano e a pesca cercando igarapés ou mesmo trechos dos rios.

A hegemonia dos missionários nos aldeamentos perdura pelo menos até meados do século XVIII quando, a partir de 1750, o diretório pombalino escreve um novo episódio na formação territorial da Amazônia com alterações nas condições de vida dos ameríndios e das populações ribeirinhas. Procurando diminuir a influência dos religiosos, tanto sobre a economia regional quanto sobre a mão de obra indígena, Marquês de Pombal introduziu uma política de centralização estatal com o propósito de consolidar o domínio português na região (TAVARES, 2011). Além da criação do Estado do Grão-Pará e Maranhão, em 1751, uma das principais medidas tomadas por Pombal nesse período foi o 
incentivo à migração de colonos portugueses para promover a agricultura na imensidão amazônica e estabelecer trocas culturais com os índios. Através do alvará régio, de 6 de julho de 1755, Marquês de Pombal declarava aceitos os índios dos antigos aldeamentos sob a condição de se incorporarem à sociedade colonial (MAUÉS, 1999). Para substituir o sistema de aldeamento foi criado o Sistema de Diretório (1757), medida que eliminou de vez o poder dos jesuítas a partir de 1759 (TAVARES, 2011).

Para integrar os índios aldeados pelos jesuítas, o governador Mendonça Furtado, nomeado por Marques de Pombal, decretou, com base na Lei de 1755, a miscigenação dos colonos com os descendentes das missões, onde se encontravam os povos ribeirinhos:

[...] o objetivo principal era a incorporação definitiva - quer dizer biológica - desses índios genéricos à sociedade colonial para constituírem uma população leal, portadora do projeto mercantilista e garantidora das fronteiras ainda abertas da Amazônia. (ARENZ, 2000, p. 40)

Além disso, para promover a colonização e produção agrícola, Mendonça Furtado institui uma política de introdução do trabalho escravo procurando reforçar o cultivo do cacau, café, algodão, cana-de-açúcar, fumo, anil e arroz, uma vez que o braço do ameríndio não era suficiente para desenvolver a agricultura. No entanto, uma vez introduzidos na Amazônia pelos colonizadores, principalmente a partir de 1755 (SALLES, 2004), os africanos escravizados constituíram a principal fonte de mão de obra utilizada nos engenhos locais a partir da segunda metade do século XVIII (CRUZ, 1973). Após o declínio dos engenhos, essa população integra-se aos povos ribeirinhos já estabelecidos às margens dos rios da região desde os aldeamentos, processo pelo qual os africanos escravizados e seus descendentes se organizam para ocupar determinadas áreas de terras na Amazônia. Em todo caso, as medidas pombalinas têm implicações na dinâmica espacial ribeirinha na Amazônia. A introdução do africano escravizado na Amazônia torna ainda mais heterogênea e complexa a formação étnico-cultural da população regional descendente do aldeamento, em especial nas áreas de várzea, uma vez que o povoamento da região foi estabelecido inicialmente no entorno dos rios. 
Ainda que se verifique a presença de africanos escravizados na Amazônia, trazidos pela Coroa antes de 1750, a sua chegada, por meio das reformas pombalinas, trouxe implicações significativas na própria dinâmica de povoamento em várias sub-regiões da Amazônia, seja como mão de obra, seja pela fuga e formação de quilombos, seja pelos espaços de resistência ao domínio do colonizador português. Este é o caso de comunidades ribeirinhas no contexto da microrregião do Baixo Tocantins, estado do Pará, especialmente dos municípios de Abaetetuba, Baião, Cametá, Igarapé Miri, Limoeiro do Ajuru, Mocajuba e Oeiras do Pará onde, hoje, temos territórios quilombolas. Parte da dinâmica de povoamento na região deu-se entre os séculos XVIII e XIX, por meio da lavoura de cana-de-açúcar e do trabalho nos engenhos que sustentou a economia de aguardente na região tendo também papel de destaque na reorganização espacial dessa porção da Amazônia Tocantina (FERREIRA, 2014).

Em se tratando da população indígena decorrente dos aldeamentos, a criação do Diretório configura-se como controle político que perdurou até o final do século XVIII tendo consequências no povoamento das áreas ribeirinhas. Conforme exposto por Maués (1999), o Diretório, extinto pela Carta Régia de Maio de 1798, visava integrar os índios à sociedade colonial nos moldes dos colonos portugueses e, ao mesmo tempo, organizar e regular as relações de trabalho entre índios e colonizadores. Quanto ao destino das populações neo-indígenas, dentre as quais as populações ribeirinhas, Arenz (2000) assinala que "em vez de permanecerem nas vilas como lugar social projetado sob tutela de um diretor branco - os tapuias espalharam-se ao longo das beiradas dos rios ou estabeleceram-se a uma certa distância das recém proclamadas vilas, lugares ocupados até hoje por seus descendentes, os ribeirinhos" (ARENZ, 2000, p. 42).

Sociedades e espaços ribeirinhos, tais como os Omágua, integravam a formação territorial da Amazônia desde os primórdios da colonização. Na pesquisa de Meggers (1987), os Omágua habitavam, em 1542, a várzea do Japurá até a metade da área situada entre Coari e o Purus. Mas, ainda segundo Meggers (1987, p. 176), "em consequência de doenças, de incursões preadoras de índios e dos ensinamentos das missões, o modo de vida dos Omágua estava quase extinto nos princípios do século XVIII”. Tanto na fase dos aldeamentos quanto na fase do diretório, os moradores das margens dos rios e igarapés 
da Amazônia foram tratados como assunto de Estado, pois "nos aldeamentos dirigidos pelos religiosos e, depois disso, nas vilas sob o comando dos diretores pretendia-se criar uma população integrada ao projeto econômico capitalista e submissa aos colonizadores" (ARENZ, 2000, p. 42). Neste sentido,

a população ribeirinha está marcada étnica e culturalmente por um relacionamento assimétrico entre os colonizadores e os povos indígenas. Mesmo sendo aceito como mão-de-obra dentro do conjunto da sociedade colonial envolvente experimentaram uma forte descriminação devido sua origem ameríndia. Até hoje esse fato impediu a autoidentificação com um grupo social com raízes históricas e étnicas no contexto macroestrutural da sociedade envolvente. (ARENZ, 2003, p. 33/34)

Ressalta-se que uma das marcas desses dois primeiros séculos de colonização foi a utilização pelo empreendimento colonial da força de trabalho dos habitantes das áreas de várzea e de terra firme da Amazônia. No entanto, conforme Arenz (2003), os ribeirinhos resistiram à ascensão e declínio de produtos que impulsionaram a economia regional. A colonização e a exploração das riquezas naturais da região prosseguiram com o extrativismo da borracha, durante fins do século XIX até meados do século XX, que escreveu um novo capítulo na formação da várzea amazônica pelos ribeirinhos, conforme será analisado a seguir.

\section{O período da borracha}

No final do século XIX, antes mesmo do auge da economia da borracha, estava delineada a composição étnica da população amazônida. Nesse momento, Bates (1979, p. 22), menciona que a maioria das tribos "estão agora extintas ou abandonadas à sua sorte, pelo menos as que povoaram primitivamente as margens do rio principal, tendo-se misturado aos seus descendentes ou a imigrantes brancos e negros". Mistura composta de,

vários tipos de mestiços [que] agora constituem provavelmente a maior parte da população [e] têm cada um, a sua denominação própria. 
Mameluco é o mestiço de índio com branco; mulato, o de branco com o negro; cafuso, o de índio com o negro; curiboca, o de cafuso com índio, e xíbaro, o de cafuso com negro. Esses tipos nunca são, entretanto, muito bem definidos, havendo entre uns e outros todos os matizes de cor possíveis e usando-se as denominações apenas para classificá-los de um modo geral. O termo crioulo é aplicado exclusivamente a negros nascidos no país. O índio civilizado é chamado tapuia ou caboclo. (BATES, 1979, p. 22)

A consolidação étnico-cultural, do que Adam, Murrieta e Neves (2006) denominam sociedades caboclas na Amazônia, teve no período da borracha um evento significativo na organização espacial das sociedades ribeirinhas, conforme sinalizam os estudos de Tocantins (1961), Weinstein (1993), Silva (2000) e Witkoski (2007). A partir da segunda metade do século XIX, com a crescente procura pela borracha no mercado mundial, iniciase uma fase de dinamismo econômico na região que tinha como base o extrativismo de um líquido leitoso e viscoso retirado da seringueira amazônica (Hevea brasiliensis). As indústrias automobilísticas europeia e norte-americana demandavam borracha dos seringais para matéria-prima e isso reverberou na reorganização regional, em especial das áreas ribeirinhas.

De acordo com Weinstein (1993), de 1877 em diante, a exploração dos seringais amazônicos exigiu grande contingente de mão de obra. Ao esforço da produção do látex, tornou-se imprescindível o "aliciamento intenso de força de trabalho capaz de azeitar o empreendimento nas duras condições de trabalho nos seringais" (Witkoski, 2007, p. 94). A coincidência entre o surto extrativo da borracha na Amazônia, a partir da década de 1870, e a grande seca da região nordeste do Brasil, entre os anos 1877-1879, propiciou circunstâncias favoráveis à vinda de grandes contingentes de nordestinos que se integraram à economia da borracha, como ressalta Weinstein (1993):

[...] em 1887, os preços da borracha começaram a subir rapidamente, estimulando o deslocamento na direção de novas zonas de seringueiras e a rápida expansão da rede comercial do Pará [...]. Quase simultaneamente uma grande seca no Nordeste do Brasil deslocou milhares de retirantes miseráveis para a Amazônia, onde os setores extrativo e agrícola precisavam desesperadamente de sua mão-de-obra. Com trabalhadores disponíveis em maior número do que a economia 
poderia finalmente absorver, e com os preços da borracha em ascensão, a Amazônia estava no limiar do período mais pujante de sua história. (WEINSTEIN, 1993, p. 88)

Na busca do ouro negro, a população fixa-se nas margens dos rios, dispersando-se pelo vale amazônico e mesmo subindo os altos cursos até então inexplorados à procura das concentrações de seringueiras na floresta. Na sua história econômica da Amazônia, Santos (2019, p. 26) estima que a população da Amazônia era de 90.000 em 1800, 389.977 em 1880 e 1.217,024 na ascensão da economia da borracha. Tem-se, a partir de 1887, um dos maiores movimentos demográficos registrados no Brasil em direção à Amazônia. Estima-se que cerca de quinhentos mil (500.000) nordestinos chegaram à região a partir de então (WEINSTEIN, 1993).

Esse movimento tem implicações na sociedade e espaço ribeirinhos. Em primeiro lugar, as famílias nordestinas recém-chegadas estabeleceram-se às margens dos rios próximos aos caminhos dos seringais. Conforme Tocantins (1961), no caso do estado do Pará, os migrantes fixaram-se nas cercanias de Belém e no Baixo-Tocantins, nos municípios banhados pela bacia do Moju, Acará, Guamá e Tocantins, como Abaetetuba, Igarapé-miri, Cametá, Mocajuba, Baião, dentre outros. A procura mais persistente da seringueira forçou as levas humanas a descerem o rio Tocantins e penetrarem na região de Breves e Anajás, na Ilha de Marajó (PA). A extração do látex obedeceu aos caprichos da geografia da seringueira, subindo o rio Amazonas até o Acre, o verdadeiro El dorado da borracha (TOCANTINS, 1961). Os seringueiros foram desbravando as matas, seguindo os cursos naturais dos rios em locais ermos e desconhecidos. Tudo impulsionado pela a supervalorização da borracha em virtude dos apelos da Europa e dos Estados Unidos.

No entanto, a partir de 1910, aos poucos desmoronaria toda a estrutura econômica da borracha na Amazônia e desapareceria o otimismo e a ostentação dos anos de prosperidade. A queda dos preços no mercado europeu, principal consumidor da borracha da Amazônia, trouxe a diminuição da produção regional que outrora assegurou os tempos de prosperidade econômica. Assim, desfez-se a ilusão e uma série de impactos 
diretos nas condições de vida de milhares de nordestinos nos seringais no entorno dos rios (GRANDIN, 2010).

A crise impossibilitou aos nordestinos retornarem ao sertão e, sem alternativa, permaneceram no espaço e sociedade da várzea tradicionalmente habitada por ribeirinhos. De acordo com Ribeiro (1995), depois da crise, grande parte dos migrantes que um dia pretendia voltar ao nordeste acabou empobrecida e ficou nos seringais, integrando-se às formas de vida regional, isto é, ao modo de vida ribeirinho através das práticas secularizadas pelas sociedades indígenas, como a pesca, a caça, e a agricultura.

No período da Segunda Guerra Mundial (1939-45) houve esforços dos governos brasileiro e americano para reaquecer a produção da borracha, pois, ocorreu a interrupção no seu fornecimento em virtude dos ataques japoneses às plantações orientais. Naquele contexto, o Estado brasileiro promoveu nova transladação de nordestinos à Amazônia. Estima-se que essa nova migração tenha envolvido de 30 a 50 mil trabalhadores (RIBEIRO, 1995). Esses refugiados da seca foram levados para o vale amazônico para engrossar a mão de obra na extração da borracha. De acordo com Silva (2000),

[...] onde tinha ocorrência de seringa a área era ocupada por seringueiros, não importando mais a distância e nem o ataque por parte dos indígenas, pois nessa época algumas aldeias já tinham sido dizimadas, principalmente as que ficavam próximas aos rios e igarapés. (SILVA, 2000, p. 89)

Tendo papel fundamental no recrutamento de trabalhadores nordestinos, o governo federal não poupou esforços no sentido de atrair brasileiros para a batalha da borracha. O presidente Getúlio Vargas buscava atrair maior número de extratores por meio de discurso patriótico e com uma intensa propaganda massificadora. Com efeito, sublinha Silva (2000), mobilizou-se verdadeiro exército, tal como soldados rumo aos campos de batalha nas selvas amazônicas. 
Porém, passada a Segunda Guerra Mundial (1939-1945) a demanda da borracha no comércio internacional foi reduzida novamente; a borracha sintética começou a concorrer mais fortemente com a natural e os seringais cultivados não se renovavam para atender à demanda. A elite regional abandonou os seringais a partir de 1950, pois os lucros obtidos agora não eram os mesmos dos períodos de ascensão e auge. O resultado desse processo para os nordestinos foi desastroso. Uma vez mais teriam de enfrentar a pobreza e o descaso por parte do governo que promoveu a sua migração.

Isso equivale a dizer que para os nordestinos a história se repetiu. Depois da decadência,

[...] muitos vieram para a cidade em busca de trabalho e estudo para os filhos e a maioria procurou as margens dos rios, lagos e igarapés e fixou residência definitiva, e paulatinamente, teve de readaptar seu modo de vida de tal forma que a atividade de extração do látex foi abandonada passando a adotar a atividade de pesca e da agricultura em pequena escala, principalmente na lavoura branca. (SILVA, 2000, p. 91)

Assim, complementa Ribeiro, (1995, p. 326),

[...] aos poucos, a população volta a concentrar-se à margem dos grandes rios navegáveis, regredindo a uma economia de subsistência e a condições de miserabilidade mais aguda do que a dos sertões de onde havia fugido. E mais difícil que a dos índios, em virtude de suas necessidades de gente "civilizada", que precisava vestir-se, curar as enfermidades com remédios comprados e suprir-se de artigos comerciais.

Essa nova situação espacial significou para os migrantes nordestinos e para o caboclo amazônida abandono e readaptação. Depois de anos de trabalho nos seringais, nordestinos e amazônidas, especialmente os ribeirinhos, mais uma vez ficaram com o ônus inerente aos períodos de ascensão e queda da economia regional dependente da aceitação internacional de um produto. 


\section{Considerações finais}

Expusemos elementos da formação do espaço e da sociedade ribeirinha na Amazônia. Mostramos que foram forjados na dialética da colonização que estrutura a região no transcorrer da história. Isso quer dizer, como bem assinalou Arenz (2000, p. 78), que "a formação histórica do projeto de vida dos ribeirinhos, apesar de sua condição específica, não pode ser considerada um processo excepcional ou um 'caso isolado”". Tal análise envolve não somente a geografia dos rios mas, sobretudo, a geografia dos seres humanos que compreende a produção histórica do espaço amazônico.

As sociedades ribeirinhas estão presentes na história da Amazônia desde antes do contato com os europeus. Daí a importância de se considerar que sua organização espacial no interior da região, por sua vez, se constrói em torno das dinâmicas econômicas e políticas europeias. Foi através dos rios que povos ameríndios estabeleceram as primeiras formas de adaptação ao ambiente amazônico, que marcaram profundamente o modo de vida de seus sucessores, os ribeirinhos; foi também através dos rios que os colonizadores garantiram a conquista do espaço amazônico no tocante ao projeto mercantilista e eurocêntrico que modelou as populações ribeirinhas nos aldeamentos missionários; e, finalmente, foi na várzea amazônica que foi escrita a saga dos migrantes nordestinos e sua integração ao modo de vida tipicamente ribeirinho.

A várzea amazônica representa, para os nativos e colonizadores, um conjunto de possibilidades, sendo que a realização de algumas exemplificava a assimetria de poder entre colonizadores (que sempre viram a região como fonte de mercadoria) e a população nativa, subjugada aos desígnios de racionalidades alheias às suas condições de vida. É nesse contexto que se pensa a formação ribeirinha não apenas como expressão de uma trajetória étnica e cultural mas, também, permeada por contradições inerentes ao sistema dominante implantado historicamente na região.

Dessa forma, entende-se que a formação da sociedade e do espaço ribeirinhos na Amazônia também representou a negação do modo de ser e de viver desses povos, compreendida não apenas no contexto da colonização europeia mas, igualmente, em diversas outras frentes de exploração econômica na região, a exemplo do período que 
marcou o extrativismo da borracha. No entanto, isso não aconteceu sem lutas e resistências frente aos desmandos do poder opressor, como a rebelião da cabanagem, entre as décadas de 30 e 40 do século XIX, tão bem analisadas por Harris (2017).

A tradição africana também tem grande influência na formação ribeirinha na Amazônia, haja vista o reconhecimento histórico da presença de africanos escravizados no Brasil na região, notadamente a partir das políticas pombalinas em 1750, que foram trazidos pela Companhia de Comércio do Grão-Pará e Maranhão, em 1755, para substituir o trabalho do indígena na lavoura (SALLES, 2004). Desse modo, fica em aberto, aqui, essa discussão considerando a necessidade de aprofundamentos do debate acerca desse processo, sem deixar de reconhecer, é claro, os esforços já empreendidos nessa direção.

A produção do espaço e da sociedade ribeirinha na Amazônia esteve tradicionalmente ligada à dinâmica dos rios. Desde os tempos mais remotos, o rio se constitui como um meio de vida essencial. O emaranhado de rios facilitou as condições de vida das populações ribeirinhas nas comunidades locais e o estabelecimento da configuração espacial a partir do século XVIII. O resgate da história da sociedade e espaço ribeirinhos na Amazônia nos permite refletir sobre as múltiplas formas de produção de territorialidades no meio rural amazônico que não podem ser vistas como tradicionais e estáticas ao movimento da sociedade como muito se advoga, mas são dinâmicas e plurais, pois essas populações também reinventam suas condições de vida para assim sobreviver frente às adversidades provenientes da chamada modernidade.

\section{Referências}

ADAMS, Cristina; MURRIETA, Rui; NEVES, Walter (orgs.). Sociedade caboclas Amazônicas: modernidade e invisibilidade. São Paulo: Annablume. 2006.

ALBUQUERQUE. Luiz R. Cavalcante de. Amazônia em 1893. Rio de Janeiro: Imprensa Nacional, 1894.

ALTVATER, Elmar. O fim do capitalismo como o conhecemos: uma crítica radical do capitalismo. Rio de Janeiro: Civilização Brasileira. 2010. 
ARENZ, Karl Heinz. Filhos e filhas do Beiradão: formação sócio-histórica dos ribeirinhos da Amazônia. Santarém: FIT, 2000.

BARATA, Manoel. Formação histórica do Pará. Belém: UFPA. 1973.

BATES, Henry. Um naturalista no Rio Amazonas. Belo Horizonte: Editora Itatiaia. 1979.

BENCHIMOL. Samuel. Formação social e cultural. Manaus: Valer. 2009.

BEZERRA NETO, José Maia. A conquista Portuguesa da Amazônia. In: ALVES FILHO, Armando; SOUZA JUNIOR, José Alves; BEZERRA NETO, José Maia. (orgs.). Pontos de história da Amazônia. 2 ed. Belém: Paka-Tatu, 2001. p. 11-25.

COSTA, Francisco de Assis. Formação agropecuária da Amazônia: os desafios do desenvolvimento sustentável. Belém: UFPA: NAEA, 2000.

CRUZ, Ernesto. História do Pará. Belém, PA: UFPA, 1973. v. 1.

DIEGUES, Antonio Carlos. O mito moderno da natureza intocada. São Paulo: Hucitec, 1996.

FERREIRA, Denison da Silva. Dinâmica socioespacial ribeirinha nas Ilhas de AbaetetubaPa. 2014. Dissertação (Mestrado em Geografia) - Universidade Federal do Pará, Belém, 2014.

FURTADO, Lurdes Gonçalves. "Reservas pesqueiras”, uma alternativa de subsistência e de preservação ambiental: reflexões a partir de uma proposta de pescadores do Médio Amazonas. In: FURTADO, Lurdes; LEITÃO, Wilma; MELLO, Alex Fiúza. (orgs.) Povos das águas: realidade e perspectivas na Amazônia. Belém: Museu Paraense Emilio Goeldi, 1993.

GONÇALVES, Walter P. Gonçalves. Amazônia, Amazônias. São Paulo: Contexto, 2001.

GONDIM, Neide. A invenção da Amazônia. 2 ed. Manaus: Valer, 2007.

GRANDIN, Greg. Fordlândia: ascenção e queda da cidade esquecida de Henry Ford na selva. Rio de Janeiro: Rocco, 2010.

HARRIS, Mark. Rebelião na Amazônia: cabanagem, raça e cultura popular no norte do Brasil: 1798-1840. Campinas: Editora Unicamp. 2017.

HÉBETTE, Jean. No mar, no rio e na fronteira: faces do campesinato no Pará. Belém: EDUFPA, 2002. 
HIRAOKA, Mário. Mudanças nos padrões econômicos de uma população ribeirinha do estuário do Amazonas. In: FURTADO, Lurdes; LEITÃO, Wilma; MELLO, Alex Fiúza (orgs.) Povos das águas: realidade e perspectivas na Amazônia. Belém: Museu Paraense Emilio Goeldi, 1993.

LOUREIRO, João de Jesus Paes. Cultura amazônica: uma poética do imaginário. São Paulo: Escrituras, 2001.

MACHADO, Lia Osório. O controle intermitente do território. Território, Rio de Janeiro, v. 1, n. 2, 1997.

MARIN, Rosa Elizabeth Acevedo. Civilização do rio, civilização da estrada: transportes na ocupação da Amazônia no século XIX e XX. Paper do NAEA, Belém, n. 170, p. 4-14, maio 2004.

MAUÉS, Raimundo Heraldo. Uma outra “invenção” da Amazônia. Belém: CEJUP, 1999.

MCGRATH, David. Varzeiros, geleiros e o manejo dos recursos naturais na várzea do Baixo amazonas. Paper do NAEA, Belém, n. 4, p. 01-25, jan. 1991.

MECOR. Operação Amazônia: relatório ministerial apresentado à consideração do Senhor Presidente da República pelo Ministro Extraordinário para Coordenação dos Organismos Regionais. [S.I.: s.n., 1960].

MEGGERS, Betty. Amazônia: a ilusão de um paraíso perdido. Belo Horizonte: Itatiaia. 1987.

NAHUM, João Santos. Região, discurso e representação: a Amazônia nos planos de desenvolvimento. Boletim Geográfico, Maringá, v. 29, n. 2, p. 17-31, 2011.

NAHUM, João Santos. Região e representação: a Amazônia nos planos de desenvolvimento. Belém: Açaí. 2013.

NAHUM, João Santos; SANTOS, Cleison Bastos dos. Do sítio camponês ao lote de dendê: transformações do espaço rural na Amazônia paraense no século XXI. Revista Nera, Presidente Prudente, ano 20, n. 37, pp. 54-76, mai./ago. 2017.

NAHUM, João Santos. Notas sobre a formação territorial da Amazônia paraense: do meio natural ao meio técnico. In: SILVA, Christian Nunes; DE PAULA, Cristiano Quaresma; SILVA, João Márcio Palheta (orgs.). Produção espacial e dinâmicas socioambientais no Brasil setentrional. Belém: GAPTA: UFPA, 2019a. p. 23-42. 
NAHUM, João Santos. Meio natural e período camponês na Amazônia paraense: notas de uma proposição metodológica. Belém: UFPA. 2019b.

PORRO, Antonio. 0 povo das águas: ensaios de etno-história amazônica. Petrópolis: Vozes, 1995.

RIBEIRO, Darcy. O povo brasileiro: a formação e o sentido do Brasil. 2 ed. São Paulo: Companhia das Letras, 1995.

SALLES, Vicente. O negro na formação da sociedade paraense. Belém: Paka-Tatu, 2004.

SANTOS, Milton. A natureza do espaço: técnica e tempo, razão e emoção. 4 ed. São Paulo: Edusp, 2006.

SANTOS, Roberto. História econômica da Amazônia (1800-1920). 2 ed. Manaus: Valer, 2019.

SILVA, Bruno Hernani. História do Brasil: geral e regional. São Paulo: Cultrix, 1996. v. 1. (Amazônia)

SILVA, Maria das Graças S. N. O espaço ribeirinho. São Paulo: Terceira Margem, 2000.

TAVARES, Maria Goretti. A Amazônia brasileira: formação histórico-territorial e perspectivas para o século XXI. GEOUSP, Espaço e Tempo, São Paulo, n 29, p. 107-121, 2011. Edição especial.

TOCANTINS, Leandro. O rio comanda a vida: uma interpretação da Amazônia. 9 ed. Manaus: Editora Valer, 2000.

WAGLEY, Charles. Uma comunidade Amazônica: estudo do homem nos trópicos. 3 ed. Belo Horizonte: Itatiaia, 1988.

WEINSTEIN, Barbara. A borracha na Amazônia: expansão e decadência, 1850-1920. São Paulo: Hucitec, 1993.

WITKOSKI, Antônio Carlos. Terras, florestas e águas de trabalho: os camponeses amazônicos e as formas de uso de seus recursos naturais. Manaus: Editora da UFAM, 2007. 
Recebido em: 06/09/2019

Aprovado em: 07/08/2019

Universidade do Estado de Santa Catarina - UDESC

Centro de Ciências Humanas e da Educação - FAED

Revista PerCursos

Volume 20 - Número 43 - Ano 2019

revistapercursos@gmail.com 